Eka P.B. Mulia, Ricardo A. Nugraha, Maya Q. A’yun, Rahima R. Juwita, Filipus M. Yofrido, Rerdin Julario and Firas F. Alkaff*

\title{
Electrocardiographic abnormalities among late-stage non-dialysis chronic kidney disease patients
}

https://doi.org/10.1515/jbcpp-2020-0068

Received March 1, 2020; accepted August 7, 2020;

published online November 4, 2020

\section{Abstract}

Objectives: Cardiovascular disease (CVD) complication is common among chronic kidney disease (CKD) patients. Thus, knowledge about CVD and ECG abnormalities in CKD are essential due to progressive nature of the disease and increased risk of sudden cardiac death. This study aims to scrutinize the ECG abnormalities among nondialysis latestage CKD patients.

Methods: A descriptive observational study was conducted at Dr. Soetomo General Hospital, Surabaya, Indonesia. Subjects were hospitalized patients with latestage CKD between 1 January and 31 December 2019, who were consulted at the department of cardiology and vascular medicine during their initial admission at emergency room. ECG interpretation for this study was done by qualified cardiologist.

Eka P.B. Mulia and Ricardo A. Nugraha contributed equally to this work.

*Corresponding author: Firas F. Alkaff, Department of Pharmacology, Faculty of Medicine Universitas Airlangga, Surabaya, Indonesia, Phone: +6281330101993, E-mail: firasfarisialkaff@fk.unair.ac.id. https://orcid.org/0000-0002-5628-1345

Eka P.B. Mulia, Ricardo A. Nugraha, Maya Q. A'yun, Rahima R. Juwita and Rerdin Julario, Department of Cardiology and Vascular Medicine, Faculty of Medicine Universitas Airlangga - Dr. Soetomo General Hospital, Surabaya, Indonesia, E-mail: eka.prasetya.budi2017@fk.unair.ac.id (E.P. Mulia), ricardo.adrian.nugraha2019@fk.unair.ac.id (R.A. Nugraha), maya.qurota.ayun2019@fk.unair.ac.id (M.Q. A’yun), rahimaratnajuwita@gmail.com (R.R. Juwita), rerdinjulario@gmail.com (R. Julario). https://orcid.org/ 0000-0002-2681-7743 (E.P. Mulia). https://orcid.org/0000-00030648-0829 (R.A. Nugraha). https://orcid.org/0000-0002-5244-3132 (M.Q. A'yun). https://orcid.org/0000-0002-7201-2460 (R. Julario) Filipus M. Yofrido, Department of Physiology, Faculty of Medicine Widya Mandala Catholic University, Surabaya, Indonesia, E-mail: filipus.michael@gmail.com. https://orcid.org/0000-00030223-5084
Results: There were 191 patients included in this study. Mean ages were $52.2 \pm 11.8$ years old and $51 \%$ were males. Total $143(74.9 \%)$ patients had anemia, $111(58.1 \%)$ had hypertension and 75 (39.3\%) had type 2 diabetes mellitus. Mean serum creatinine was $10.5 \pm 8.0 \mathrm{mg} / \mathrm{dL}$. There were 176 (92.1\%) patients with at least one form of ECG abnormalities. Prolonged QTc interval (36.6\%), fragmented QRS complex (29.8\%), poor $\mathrm{R}$ wave progression (24.6\%), peaked T wave (22.0\%) and left ventricular hypertrophy (16.7\%) were the most common abnormalities.

Conclusions: ECG abnormalities are common among nondialysis late-stage CKD patients. Given the fact that long-term CKD influences the pathogenesis cardiovascular diseases and substantial cardiovascular mortality, there is a need to screen Indonesian CKD patients who are at risks of getting earlier complications.

Keywords: cardiovascular disease; chronic kidney diseases; electrocardiogram.

\section{Introduction}

Chronic kidney disease (CKD) is described as a kidney abnormalities stages, both structure and/or function, persist for more than 3 months, with many health implications [1]. CKD still becomes a major public health problem. Estimated global prevalence in CKD is consistent between 11 and 13\% with the majority of stage 3 [2]. In Indonesia, CKD was found in $7.5 \%$ subjects with hypertension (HTN), proteinuria and/or diabetes [3].

CKD has a strong association with increased rates of hospitalization, morbidity and mortality [4]. CKD also increases the risk of cardiovascular disease (CVD) even from early stage before ESRD. Cardiovascular complication is the highest cause of mortality in late-stage CKD patients, this rate higher in dialysis patients than nondialysis $[5,6]$. In patients undergoing dialytic therapy, sudden cardiac death (SCD) accounts for approximately $60 \%$ of cardiacrelated deaths, and the rate of mortality due to cardiac arrest is 93 events/(1000 patients/year) in the first year of dialysis [7]. 
Although modern diagnostic technology is highly developed, electrocardiogram (ECG) is still a simple, noninvasive and useful diagnostic tool for diagnosing the majorityasymptomatic progressive nature of CVD morbidity and mortality in late-stage CKD patients [8, 9]. In limited setting, ECG is able to detect heart rhythm disturbances, cardiac conduction abnormalities, chambers abnormalities and sign of myocardial ischemia [4]. Abnormalities of ECG that occur in late-stage CKD patients can be independently estimate future CVD and risk of sudden death. However, various kinds in the prevalence of ECG abnormalities had been reported in several previous studies.

In addition, the limited studies that provide information on the variety of ECG changes prevalence in the local CKD population can make the physician less aware of the complications of CVD in late-stage CKD. The prevalence of ECG changes in local CKD patients in Indonesia may also be different from the other studies and literature that has been reported. The aim of this study was to scrutinize the ECG abnormalities among nondialysis late-stage CKD patients.

\section{Materials and methods}

This was a descriptive observational study using cross-sectional design, conducted at Dr. Soetomo General Hospital, Surabaya, Indonesia. This hospital is one of the biggest hospitals in Indonesia and also being functioned as referral hospitals for East Indonesia region. The study was conducted from 1 January to 31 December 2019. All adult patients with late-stage CKD (stage 3B, 4 and 5) that was hospitalized during the study period and consulted at department of cardiology and vascular medicine during their initial admission at emergency room were included in this study. Patients with previously hemodialysis, unstable hemodynamic, history of cardiac arrest, previously consumed antiarrhythmic drugs and lack of complete medical record data were excluded.

All patients gave their informed consent prior to their inclusion in this study. Information for informed consent was given before the participants signed the informed consent. Details that might disclose the identity of the participants were omitted. This study followed the principles of the Declaration of Helsinki and had been approved by the ethical committees of Dr. Soetomo General Hospital (Ethical clearance number: 1811/KEPK/II/2020).

All patients had resting 12-lead ECG examination. All ECGs were reviewed by qualified cardiologist for the following parameters: heart rhythm, heart rate, frontal axis, P wave, PR interval, QRS duration, pathological Q wave, fragmented QRS morphology, ST-segment deviation, QT interval and $\mathrm{T}$ wave abnormality. The aforementioned parameters were studied and measured manually and compared with published normal values. Normal limit and definition used for this study were shown in Table 1 and Table 2.

All statistical analyses were performed using SPSS 25.0 (IBM Corp., Armonk, N.Y., USA). For descriptive analysis, continuous data were given as mean $\pm \mathrm{SD}$ or median (IQR) based on data distribution, while categorical data were given as $\mathrm{n}(\%)$. One-Sample KolmogorovSmirnov was used to assess the data distribution.
Table 1: Normal limit for electrocardiographic parameters.

\begin{tabular}{ll}
\hline Parameters & Normal limit [37] \\
\hline Rhythm & $\begin{array}{l}\text { Sinus rhythm (Positive P wave in I, II, aVF and no } \\
\text { AV dissociation) }\end{array}$ \\
Heart rate & $60-100 \mathrm{bpm}$ \\
Frontal axis & -30 to $+90^{\circ}$ \\
P Wave & $<120 \mathrm{~ms}$ in duration and $<2.5 \mathrm{~mm}$ in amplitude \\
PR Interval & $120-200 \mathrm{~ms}$ \\
QRS Complex & $<120 \mathrm{~ms}$ and no fragmented QRS \\
Q Wave & Depth $<1 / 4$ amplitude deflection of R wave \\
& and $\leq 40 \mathrm{~ms}$ \\
QT Interval & Corrected QT interval by Bazzet's formula \\
& $330-440 \mathrm{~ms}$ in male or 330-450 in female \\
ST-Segment & Deviation at J-point $<1 \mathrm{~mm}$ \\
T Wave & No inverted T wave except in lead III, aVR and V1 \\
\hline
\end{tabular}

$\mathrm{bpm}$, beats per minute; $\mathrm{mm}$, millimeter; $\mathrm{ms}$, millisecond.

\section{Results}

There were 191 patients included in this study. Mean age was $52.2 \pm 11.8$ years old. Total number of male and female was almost equal. Most patients were in CKD stage 5 . Mean creatinine serum was $10.5 \pm 8.0 \mathrm{mg} / \mathrm{dL}$ and mean eGFR was $9.6 \pm 4.4 \mathrm{~mL} / \mathrm{min} / 1.73 \mathrm{~m}^{2}$. There were $143(74.9 \%)$ patients with anemia (mean hemoglobin concentration was $8.1 \pm 2.3 \mathrm{~g} / \mathrm{dL}$ ), 111 (58.1\%) patients with HTN (Mean systolic blood pressure was $142.1 \pm 28.2 \mathrm{mmHg}$ and mean diastolic blood pressure was $83.7 \pm 16.3 \mathrm{mmHg}$ ) and 75 (39.3\%) with type 2 diabetes mellitus. Mean serum potassium of the patients in this study was $4.8 \pm 1.06 \mathrm{mEq} / \mathrm{L}$. There were only $5.8 \%$ patients with very high serum potassium level (>6.5 mEq/L) (Table 3).

Resting 12-lead ECG examination showed that the mean heart rate was $92.2 \pm 15.6$ beats per minute, mean PR interval was $157.3 \pm 32.2 \mathrm{~ms}(\mathrm{~ms})$, mean QRS duration $87.9 \pm 17.9 \mathrm{~ms}$ and mean QTc interval was $442.9 \pm 37.6 \mathrm{~ms}$. At least one ECG abnormalities was found in 176 (92.1\%) patients. The most common ECG abnormalities found were prolonged QTc interval (36.6\%), fragmented QRS complex (fQRS) (29.8\%), poor R wave progression (PRWP) (24.6\%), peaked T wave (22.0\%) and left ventricular hypertrophy (LVH) (16.7\%) (Table 4).

\section{Discussion}

From previous epidemiological studies, patients with CKD are more susceptible in developing CVD. CVD can kill patients with CKD more often and more prematurely. The CVD spectrum in CKD and ESRD includes ischemic 
Table 2: Definition used to determine ECG abnormality.

\begin{tabular}{|c|c|}
\hline ECG Abnormality & Definition Used \\
\hline FQRS complex & Additional spikes within the QRS complex [38] \\
\hline \multirow[t]{7}{*}{ LBBB } & 1) QRS duration $\geq 120 \mathrm{~ms}$, \\
\hline & $\begin{array}{l}\text { 2) Broad notched or slurred R wave in leads I, aVL, V5 and V6 and an occasional RS pattern in V5 and V6 } \\
\text { attributed to displaced transition of QRS complex, }\end{array}$ \\
\hline & $\begin{array}{l}\text { 3) Absent } Q \text { waves in leads I, V } 5 \text { and V6 or a narrow } Q \text { wave in the absence of myocardial pathology in the } \\
\text { lead aVL, }\end{array}$ \\
\hline & $\begin{array}{l}\text { 4) R peak time greater than } 60 \text { ms in leads V5and V6 but normal in leads V1, V2 and V3, when small initial } R \\
\text { waves can be discerned in the above leads, }\end{array}$ \\
\hline & 5) ST and T waves opposite in direction to QRS, \\
\hline & 6) Positive T wave in leads with upright QRS, \\
\hline & 7) Depressed ST segment and/or negative T wave in leads with negative QRS [39] \\
\hline \multirow[t]{2}{*}{ RBBB } & 1) $\mathrm{QRS}$ duration $\geq 120 \mathrm{~ms}$ \\
\hline & 2) $r s r^{\prime}, r s R^{\prime}$ or $r S R^{\prime}$ in leads V1or $V 2$ where the $\mathrm{R}^{\prime}$ or $\mathrm{r}^{\prime}$ deflection is wider than the initial $\mathrm{R}$ wave [39] \\
\hline Poor $\mathrm{R}$ wave progression & $\mathrm{R}$ wave in $\mathrm{V} 3$ or $\mathrm{V} 4 \leq 2 \mathrm{~mm}[40]$ \\
\hline \multirow[t]{6}{*}{ LAE } & Any one of the following: \\
\hline & 1) $P$ wave in any lead $>0.11 \mathrm{~s}$, \\
\hline & 2) Notched $P$ wave with interpeak duration $>0.04 \mathrm{~s}$, \\
\hline & 3) $\mathrm{P}$ wave axis $<30^{\circ}$, \\
\hline & 4) Area of negative $P$ terminal force in lead $V 1>0.04 \mathrm{~s} \mathrm{~mm}$, or \\
\hline & 5) Positive $P$ terminal force in lead $\mathrm{aVL}>0.5 \mathrm{~mm}[41]$ \\
\hline LVH & $\begin{array}{l}\text { The sum of the } S \text { wave amplitude in lead V1 and the largest amplitude of R wave in either lead V } 5 \text { or } \\
\text { V6 } \geq 35 \mathrm{~mm}[42]\end{array}$ \\
\hline \multirow[t]{3}{*}{ RAE } & Any one of the following: \\
\hline & 1) $\mathrm{P}$ wave in inferior leads II, III, aVF > $2.5 \mathrm{~mm}$ or \\
\hline & 2) Positive $P$ wave in $\mathrm{V} 1>1.5 \mathrm{~mm}[41]$ \\
\hline \multirow[t]{10}{*}{ RVH } & Any one of the following: \\
\hline & 1) Tall R V1 > $6 \mathrm{mV}$, \\
\hline & 2) Increased R:S ratio V1 > 1.0, \\
\hline & 3) Deep S V5 > $10 \mathrm{mV}$, \\
\hline & 4) Deep S V6 > $3 \mathrm{mV}$, \\
\hline & 5) Small S V1<2 mV, \\
\hline & 6) Small R V5,6 $<3 \mathrm{mV}$, \\
\hline & 7) Reduced $R$ :S ratio V5 $<0.75$, \\
\hline & 8) Reduced R:S ratio V6 $<0.4$, or \\
\hline & 9) Presence of QR V1 [43] \\
\hline ST-Elevation & $\begin{array}{l}\text { Two contiguous leads with ST-segment elevation } \geq 2.5 \mathrm{~mm} \text { in men }<40 \text { years, } \geq 2 \mathrm{~mm} \text { in men } \geq 40 \text { years, } \\
\text { or } \geq 1.5 \mathrm{~mm} \text { in women in leads V2-V3 and/or } \geq 1 \mathrm{~mm} \text { in the other leads in the absence of LVH or LBBB [44] }\end{array}$ \\
\hline ST-Depression & $\begin{array}{l}\text { Depression of the ST-segment of } \geq 0.05 \mathrm{mV} \text { below the isoelectric line in leads } \mathrm{V} 2 \text { and } \mathrm{V} 3 \text { and } \geq 0.1 \mathrm{mV} \text { in the } \\
\text { other lead [ } 45 \text { ] }\end{array}$ \\
\hline Inverted T wave & Inverted T wave deeper than $1 \mathrm{~mm}[45]$ \\
\hline \multirow[t]{4}{*}{ Non-specific ST-T changes } & $\begin{array}{l}\text { 1) No ST-T depression } \geq 0.5 \mathrm{~mm} \text { but ST-segment down-sloping and ST-segment or T-wave nadir at least } \\
0.5 \mathrm{~mm} \text { below the P-R baseline in any of leads I, II, aVL, or V2 to V6 }\end{array}$ \\
\hline & 2) ST-J depression $\geq 1.0 \mathrm{~mm}$ and ST-segment up-sloping or U-shaped in any of leads I, II, aVL, or V1 to V6 \\
\hline & $\begin{array}{l}\text { 3) T-wave amplitude zero (flat), negative, or diphasic (negative-positive type only) with }<1.0 \mathrm{~mm} \text { negative } \\
\text { phase in leads I, II, aVL, or V3 to V6 when R-wave amplitude is } \geq 5.0 \mathrm{~mm} \text {, }\end{array}$ \\
\hline & $\begin{array}{l}\text { 4) T-wave amplitude positive and T- to R-wave amplitude ratio of }<1: 20 \text { in any of leads I, II, aVL, or V3 to V6 } \\
\text { when } R \text { wave amplitude in the corresponding leads was } \geq 10.0 \mathrm{~mm} \text { [46] }\end{array}$ \\
\hline Pathologic Q wave & $\begin{array}{l}\text { Any } Q \text { wave with more than } 40 \text { ms width or a depth more than one-third of the adjacent } R \text { wave in more than } \\
\text { two adjacent leads [47] }\end{array}$ \\
\hline Peaked T wave & $\begin{array}{l}\text { Subjective assessment of peaked T wave morphology (narrow, symmetric and tall T wave or T/R ra- } \\
\text { tio } \geq 0.75 \text { ) [48] }\end{array}$ \\
\hline Low voltage & Peak-to-peak QRS voltage $<5 \mathrm{~mm}$ in all limb leads and $<10 \mathrm{~mm}$ in all precordial leads [49] \\
\hline
\end{tabular}

fQRS, fragmented QRS; LAE, left atrial enlargement; LBBB, left bundle branch block; LVH, left ventricular hypertrophy; mm, millimeter; $\mathrm{ms}$, millisecond; mV, millivolt; RAE, right atrial enlargement; RBBB, right bundle branch block; RVH, right ventricular hypertrophy. 
Table 3: Baseline characteristic of study population.

\begin{tabular}{|c|c|}
\hline Variables & $\mathrm{N}=191 \mathrm{n}(\%)$ \\
\hline \multicolumn{2}{|l|}{ Sex } \\
\hline Male & 95 (49.7) \\
\hline Female & $96(50.3)$ \\
\hline \multicolumn{2}{|l|}{ Age group (in years) } \\
\hline$\leq 30$ & $10(5.2)$ \\
\hline $31-40$ & $25(13.1)$ \\
\hline $41-50$ & $37(19.4)$ \\
\hline $51-60$ & $77(40.3)$ \\
\hline $61-70$ & $33(17.3)$ \\
\hline$>70$ & $9(4.7)$ \\
\hline \multicolumn{2}{|l|}{ Comorbidities } \\
\hline Anemia & $143(74.9)$ \\
\hline Hypertension & $111(58.1)$ \\
\hline Type 2 Diabetes Mellitus & $75(39.3)$ \\
\hline Metabolic Acidosis & $63(33.0)$ \\
\hline Pneumonia & $48(25.1)$ \\
\hline Hypoalbuminemia & $48(25.1)$ \\
\hline Hyponatremia & 38 (19.9) \\
\hline Pleural Effusion & $30(15.7)$ \\
\hline Pulmonary Edema & $29(15.2)$ \\
\hline Nephrolithiasis & $14(7.3)$ \\
\hline Pericardial Effusion & $1(0.5)$ \\
\hline \multicolumn{2}{|l|}{ CKD Staging } \\
\hline Stage 3B (GFR $30-44 \mathrm{~mL} / \mathrm{min} / 1.73 \mathrm{~m}^{2}$ ) & $8(4.2)$ \\
\hline Stage 4 (GFR $15-29 \mathrm{~mL} / \mathrm{min} / 1.73 \mathrm{~m}^{2}$ ) & $23(12.0)$ \\
\hline Stage $5\left(G F R<15 \mathrm{~mL} / \mathrm{min} / 1.73 \mathrm{~m}^{2}\right)$ & $160(83.8)$ \\
\hline \multicolumn{2}{|l|}{ Potassium serum level (mEq/L) } \\
\hline Hypokalemia (<3.5 mEq/L) & $16(8.4)$ \\
\hline Normokalemia (3.5-5.0 mEq/L) & $88(46.1)$ \\
\hline Hyperkalemia (> 5.0-6.5 mEq/L) & $75(39.3)$ \\
\hline Severe hyperkalemia (> $6.5 \mathrm{mEq} / \mathrm{L})$ & $11(5.8)$ \\
\hline
\end{tabular}

CKD, chronic kidney disease; GFR, glomerular filtration rate; $\mathrm{mEq} / \mathrm{L}$, milliequivalent per Liter.

heart disease, congestive heart failure, arrhythmias and peripheral vascular disease. Initially, it was estimated that this only occurred in the ESRD population which was 20-30 times more likely to die from CVD compared to the general population. However, this increased risk is spread across the CKD spectrum at all stages of CKD [10].

Anemia and hypertension were the most common comorbidities in our study and may become the main contributory factors in ECG abnormality. Anemia was found in $74.9 \%$ of our study population. Low levels of hemoglobin are associated with $\mathrm{LVH}$, increasing of hospital admission rate and downgraded quality of life [11]. Hypertension existed in $58.1 \%$ of our subjects. The prevalence of HTN in CKD population depends on the stage of CKD and its cause. The pathophysiology of HTN in developing CKD includes salt retention, volume overload, sympathetic overactivity, endothelial dysfunction and blood pressure-associated hormonal disturbance.
Table 4: Electrocardiographic Abnormalities.

\begin{tabular}{|c|c|}
\hline Abnormalities & $\mathrm{N}=191 \mathrm{n}(\%)$ \\
\hline \multicolumn{2}{|l|}{ Ischemia } \\
\hline Fragmented QRS complex & $57(29.8)$ \\
\hline Pathological Q wave & $26(13.6)$ \\
\hline Inverted T wave & $14(7.3)$ \\
\hline ST Segment depression & $13(6.8)$ \\
\hline ST Segment elevation & $2(1.0)$ \\
\hline \multicolumn{2}{|l|}{ Chamber dilatation } \\
\hline Left atrial enlargement & $46(24.0)$ \\
\hline Left ventricular hypertrophy & $32(16.7)$ \\
\hline Right atrial enlargement & $2(1.0)$ \\
\hline Right ventricular hypertrophy & $5(2.6)$ \\
\hline \multicolumn{2}{|l|}{ Electrolyte imbalance } \\
\hline Prolonged QT interval & $70(36.6)$ \\
\hline Peaked T wave & $42(22.0)$ \\
\hline \multicolumn{2}{|l|}{ Blocks } \\
\hline 1st Degree atrioventricular block & $14(7.3)$ \\
\hline Right bundle branch block & $11(5.8)$ \\
\hline Wide QRS complex & $7(3.7)$ \\
\hline Left bundle branch block & $1(0.5)$ \\
\hline 2nd Degree atrioventricular block & $1(0.5)$ \\
\hline \multicolumn{2}{|l|}{ Arrhythmia } \\
\hline Premature ventricular contraction & $5(2.6)$ \\
\hline Atrial fibrillation & $4(2.1)$ \\
\hline Premature atrial contraction & $1(0.5)$ \\
\hline \multicolumn{2}{|l|}{ Others } \\
\hline Poor precordial $\mathrm{R}$ wave progression & $47(24.6)$ \\
\hline Non-specific ST-T changes & $24(12.6)$ \\
\hline Frontal axis deviation & $21(11.0)$ \\
\hline Low voltage & $3(1.6)$ \\
\hline Short QT Interval & $1(0.5)$ \\
\hline
\end{tabular}

Uncontrolled HTN is also correlated with greater risk for cardiovascular (CV) morbidity and mortality in CKD [12].

Our study showed that abnormal ECGs were found in 92.1\% of all CKD patients. This is higher than previous studies, where abnormal ECG measurements were found in $50-86 \%$ of all patients $[4,6,11,13,14]$. In this study, prolonged QTc interval was the most common ECG finding observed. Study by Yadla and Poosa showed that prolonged QTc was found in 13.3\% of CKD population [13]. Nie et al. showed that $65 \%$ of patient undergoing hemodialysis (HD) had prolonged QTc interval [15]. These ECG markers are also useful to detect silent CV disease in the CKD setting [16]. This result also found in Bignotto et al.; approximately half of the dialysis studied population had prolonged QTc [6]. Prolonged QTc is reported to be very common in patients on HD and the factors associated with the same were found to be abnormal levels of serum calcium, phosphorus, potassium, ferritin, uric acid and BNP. Recent studies showed the significant association between interval of QTc and sudden cardiac death in 
hypertrophic cardiomyopathy and vascular calcification, helped us to recognize the essentials of QTc interval as risk evaluation in patients undergoing dialysis for SCD event. QTc interval presents more frequently as the stage of CKD progressing, but in dialysis patients, QTc interval was not significantly dissimilar as compared to nondialysis ESRD patients [17]. The phenomenon of higher serum creatinine correlate with long QTc interval could be explained by numerous factors influencing the QT interval: 1) Patients with CKD often take many medications that can cause QT prolongation; 2) Secondary hyperparathyroidism, a common complication of CKD, could lead to hypocalcemia and hypomagnesemia; 3) Renal anemia, anisocytosis and macrocytosis are also associated to long QT due to subsequent hypoxia, autonomic dysfunction and decreased myocardial oxygen supply; 4) Disturbance of delayed rectifier potassium channels; 5) Hypertension can significantly reduce potassium current densities (Ipeak, Ito, IKur, Iss and Ik1) and increase the L-type calcium channel and 6) Reactive oxygen species and uremic toxin leading to inflammatory condition and oxidative stress itself may also predispose to cardiac electrical remodeling $[18,19]$. Therefore, the prolongation of the QTC interval is common in hospitalized patients with CKD.

fQRS became the second most common abnormality found in our study. It was a marker of heterogeneous depolarization of ventricular myocardium caused by myocardial fibrosis and myocardial scarring. Cardiac remodeling is one of the significant myocardial structural abnormality in CKD patients [20]. While prevalence of $\mathrm{fQRS}$ is uncommon in population of previous study. Terho et al. found fQRS in 9.2\% of Finnish middle-aged healthy subjects [21]. Adar et al. evaluated the frequency and association of fQRS with asymptomatic left ventricle (LV) dysfunction in individuals with CKD. In general, the prevalence of fQRS was about $60 \%$ among CKD patients with preserved LV ejection fraction. In addition, fQRS was independently correlated with asymptomatic LV dysfunction in CKD patients [22]. The previous study by Liu et al. mentioned that fQRS prevalence was 30.32\% (94 of 310 patients). The distribution of fQRS in CKD Stage 3, 4 and 5 patients were $30.77,20.00$ and $32.03 \%$, respectively. In the inferior leads, fQRS was more frequent $(53.19 \%)$, compared to anterior $(21.28 \%)$ and the lateral leads $(25.53 \%)$. However, lateral leads fQRS was strongly associated with a lower LV ejection fraction [23]. Our result is consistent with Adar et al. and Liu et al., which showed that $\mathrm{fQRS}$ is one of the common findings among our CKD patients (29.8\%). In contrast with Liu et al., our study did not specify the location of fQRS. Liu et al. also stated that anterior and inferior fQRS were not related with an escalating risk of morbidity and mortality even in individuals with a previously known cardiac disease. On the contrary, lateral fQRS predicted, arrhythmic, cardiac and all-cause death in those individuals [23].

PRWP was frequently found in $24.6 \%$ of our population. Previous studies by Yadla and Poosa also showed that PRWP was common in patients on maintenance HD (11.6\%) [13]. Zema and Kligfield identified that PRWP might be caused by previous anterior acute myocardial infarction, $\mathrm{LVH}$, type $\mathrm{C}$ right ventricular hypertrophy (RVH) or may exist in otherwise healthy subjects [24].

Patients with CKD, especially in the advanced stage, are at a higher risk for incident of CVD complication and sudden cardiac death than the general population. Previous population-based research including 18,864 samples in 2012, shown silent MI (SMI) increased with decreasing eGFR from $4 \%$ in those with eGFR $\geq 60 \mathrm{~mL} / \mathrm{min} / 1.73 \mathrm{~m}^{2}$ to $13 \%$ with eGFR $<30 \mathrm{~mL} / \mathrm{min} / 1.73 \mathrm{~m}^{2}$ [25]. In patients with CKD, SMI was independently associated with worse outcomes during follow-up [26]. In previous study by Shafi et al. [4], pathologic $Q$ waves and deviation of ST-segment were found in 23.4 and $27.2 \%$, respectively; and these were similar to our study: frequency of Q waves, ST-segment elevation and ST-segment depression were 13.6, 1.0 and $6.8 \%$, respectively. Inverted $\mathrm{T}$ wave which may become one of ECG signs of CAD was also found in $7.3 \%$ in our CKD patient.

Hyperkalemia is associated with progressing ECG abnormalities starting from tall and peaked $\mathrm{T}$ waves, reduced QT interval, followed by prolonging of the PR interval and widening QRS duration, disappearing of the $P$ wave, appearing idioventricular rhythms and significant broadening of the QRS up to a sine-wave pattern. In our study, hyperkalemia is found in $45.5 \%$ population. Peaked T wave as one of the most common ECG changes caused by hyperkalemia was found in $22 \%$ population in our study. While several other ECG abnormalities that may be caused by hyperkalemia in our study include 1st Degree trioventricular block (AV block) (7.3\%), wide QRS complex (3.7\%) and short QTc interval (0.5\%). Activation of the potassium channels can accelerate membrane repolarization, then overall membrane depolarized which inactivates sodium channels [27]. Accelerated cardiac action potential repolarization causes $\mathrm{T}$ waves tenting.

Recent studies support the hypothesis of association between systolic dysfunction and LVH regression in baseline and one-year dialysis ECG of CKD patients with a 
lower risk of new-onset heart failure [11]. In our study, the ECG marker associated with chamber dilatation found are left atrial enlargement (LAE) (24\%), LVH (16.7\%), RVH $(2.6 \%)$ and right atrial enlargement $(1 \%)$. The prevalence of LVH in ESRD is vary, depending on the characteristic of the study population. Previous studies showed that the prevalence of $\mathrm{LVH}$ are around $40 \%[8,11]$, but other study showed that the prevalence was $80 \%$ [28]. The causes of CKD seem to have contributed on the ECG abnormality as prevalence of LVH and LAE were greatest among, diabetic nephropathy, hypertensive renal disease and chronic glomerulonephritis [17].

Non-specific ST-T changes were found in $12.6 \%$ of the population. This result is lower than previous studies presented nonspecific ST-T changes in 30\% of cases [29]. Badheka et al. stated that nonspecific ST-T changes on ECG were correlated with a greater prevalence of CVD risk factors in the common population. The further investigation suggests that clinical events can be preceded by depolarization and repolarization abnormalities, while isolated nonspecific ST-T changes on ECG were associated with increasing risk of cardiovascular morbidity and all-cause mortality [30].

The importance of determining the electrical axis is essential in the identification of subtle early caution indicators of any cardiovascular alterations of the patient [31]. Furthermore, previous research by Rodriguez et al. showed that the QRS frontal axis was more leftward in the population with significant microalbuminuria [32]. Sachdeva et al. also showed left axis deviation in $15 \%$ of their CKD patients [14]. Our study showed the frequency of frontal axis deviation was found in 11\% CKD patients without further investigation of the microalbuminuria status. In contrast with previous studies, Korkmaz et al. found changes in the QRS axis are rarely emphasized in such patients and no significant differences was seen in the QRS axis in HD patients with or without CVD [33].

Cohort studies by Flueckiger et al. found nearly $10 \%$ of the ESRD population evaluated for renal transplantation had a prolonged PR interval. Risk of death was twice as high for patients with $P R>200$ ms compare to patients with $\mathrm{PR} \leq 200 \mathrm{~ms}$ [34]. As mentioned in the previous study conducted by Mandic et al., among 140 patients with routine HD, first degree AV block was found in 2.9\% patients, but there were no second- and third-degree AV blocks [35]. These findings were consistent with our result that showed 7.3\% CKD patients with first degree AV Block and only $0.5 \%$ patient with second-degree AV block.

Other arrhythmias including conduction abnormalities were found in our study were right bundle branch block (RBBB) (5.8\%) and left bundle branch block (LBBB) $(0.5 \%)$. Our results were lower than the recent research by Bignotto et al. which showed the prevalence of RBBB and LBBB were 10.05 and $15.08 \%$, respectively [6]. Shafi et al. also found a higher prevalence of RBBB as $12.8 \%$ than LBBB as 9.6\% [4]. Premature ventricular contraction (PVC) and premature atrial contraction (PAC) were also found in our study with prevalence of 2.6 and $0.5 \%$, respectively. Yadla showed PVC prevalence of $6 \%$, while Shafi et al. showed PVC prevalence of $15.2 \%$ and PAC $4.8 \%$ [4, 13]. Atrial fibrillation (AF) (2.1\%) was the most common nonsinus rhythm found in our study, while the rest was junctional rhythm (0.5\%). Previous study by Bignotto et al. also showed AF was the most common nonsinus rhythm (4.44\%) in chronic HD patients [6]. CKD patients at all stages may have a broad spectrum of cardiac arrhythmias, including AF, supraventricular tachycardias, PVC, sustained "malignant" ventricular tachyarrhythmias and SCD. In later stages, bradyarrhythmias and asystole associated with hyperkalemia or another electrolyte imbalance may also present. Pathophysiology of arrhythmias in patients with CKD is related to many changes in cardiac or noncardiac factors in CKD, such as: LVH, fibrosis, autonomic imbalance, rapid fluid and electrolyte shifts [36].

There were several limitations in our study. First, further risk factors for ECG abnormalities were not taken into account for the analysis. Second, this was a crosssectional study, single center with small sample sizes in once measurement. Third, necessary information such as echocardiography or chest X-ray may be unavailable. The strength of this study was data collected actually, prevalence estimation could be done consecutively, complete study populations makes selection bias minimally and collect data process independently.

\section{Conclusions}

ECG abnormalities are common among nondialysis latestage CKD patients. The most common features of resting ECG patterns observed in those patients were prolonged QTc interval and fragmented QRS. Poor Precordial R Wave Progression, Peaked T wave and left ventricular hypertrophy were also common patterns in nondialysis late-stage CKD patients. Given the fact that long-term CKD influences the pathogenesis of cardiorenal syndromes, cardiovascular risk factors, cardiovascular diseases and substantial cardiovascular mortality, there is a need to screen Indonesian CKD patients who are at risks of getting earlier complications. 
Research funding: None declared.

Author contributions: All authors have accepted responsibility for the entire content of this manuscript and approved its submission.

Competing interests: All authors state no conflict of interest.

Informed consent: Informed consent was obtained from all individuals included in this study.

Ethical approval: The research related to human use has complied with all the relevant national regulations, institutional policies and in accordance with the tenets of the Helsinki Declaration, and has been approved by the authors' Institutional Review Board (Ethical clearance number: 1811/KEPK/II/2020).

\section{References}

1. KDIGO. KDIGO 2017 clinical practice guideline update for the diagnosis, evaluation, prevention, and treatment of chronic kidney disease-mineral and bone disorder (CKD-MBD). Kidney Int Suppl 2017;7:1-59.

2. Hill NR, Fatoba ST, Oke JL, Hirst JA, O'Callaghan CA, Lasserson DS, et al. Global prevalence of chronic kidney disease - a systematic Review and meta-analysis. PloS One 2016;11: e0158765.

3. Prodjosudjadi W, Suhardjono SK, Widiana IG, Loekman JS, Nainggolan G, Prasanto H, et al. Detection and prevention of chronic kidney disease in Indonesia: initial community screening. Nephrology 2009;14:669-74.

4. Shafi S, Saleem M, Anjum R, Abdullah W, Shafi T. ECG abnormalities in patients with chronic kidney disease. J Ayub Med Coll Abbottabad 2017;29:61-4.

5. Matsushita K, van der Velde M, Astor BC, Woodward M, Levey AS, de Jong PE, et al. Association of estimated glomerular filtration rate and albuminuria with all-cause and cardiovascular mortality in general population cohorts: a collaborative meta-analysis. Lancet 2010;375:2073-81.

6. Bignotto LH, Kallás ME, Djouki RJT, Sassaki MM, Voss GO, Soto $\mathrm{CL}$, et al. Electrocardiographic findings in chronic hemodialysis patients. J Bras Nefrol 2012;34:235-42.

7. Shastri S, Sarnak MJ. Cardiovascular disease and CKD: core curriculum 2010. Am J Kidney Dis 2010;56:399-417.

8. Stewart GA, Gansevoort RT, Mark PB, Rooney E, Mcdonagh TA, Dargie HJ, et al. Electrocardiographic abnormalities and uremic cardiomyopathy. Kidney Int 2005;67:217-26.

9. Whitman IR, Feldman HI, Deo R. CKD and sudden cardiac death: epidemiology, mechanisms, and therapeutic approaches. J Am Soc Nephrol 2012;23:1929-39.

10. Subbiah AK, Chhabra YK, Mahajan S. Cardiovascular disease in patients with chronic kidney disease: a neglected subgroup. Heart Asia 2016;8:56-61.

11. Chijioke A, Makusidi A, Kolo P. Electrocardiographic abnormalities among dialysis naïve chronic kidney disease patients in Ilorin Nigeria. Ann Afr Med 2012;11:21.

12. Ku E, Lee BJ, Wei J, Weir MR. Hypertension in CKD: core curriculum 2019. Am J Kidney Dis 2019;74:120-31.
13. Yadla M, Poosa K. Resting ECG abnormalities in patients on maintenance hemodialysis - a clinical study. IOSR-JDMS 2017; 16:62-4.

14. Sachdeva S, Khurana T, Kaur S, et al. ECG and ECHO changes in CKD. Ann Int Med Dent Res 2017;2.

15. Nie Y, Zou J, Liang Y, Shen B, Liu Z, Cao X, et al. Electrocardiographic abnormalities and QTc interval in patients undergoing hemodialysis. PloS One 2016;11: e0155445.

16. Kestenbaum B, Rudser KD, Shlipak MG, Fried LF, Newman AB, Katz R, et al. Kidney function, electrocardiographic findings, and cardiovascular events among older adults. Clin J Am Soc Nephrol 2007;2:501-8.

17. Matsumoto Y, Mori Y, Kageyama S, Arihara K, Sato H, Nagata K, et al. Changes in QTc interval in long-term hemodialysis patients. PloS One 2019;14:e0209297.

18. Liu P, Han D, Sun X, Tan H, Wang Z, Liu C, et al. Prevalence and risk factors of acquired long QT syndrome in hospitalized patients with chronic kidney disease. J Invest Med 2019;67:289-94.

19. Bodi I, Grünert SC, Becker N, Stoelzle-Feix S, Spiekerkoetter U, Zehender M, et al. Mechanisms of acquired long QT syndrome in patients with propionic academia. Heart Rhythm 2016;13: 1335-45.

20. Mittal S, Fragmented QRS. A simple electrocardiographic prognostic marker in cardiovascular disease. J Clin Prev Cardiol 2016;5:94.

21. Terho HK, Tikkanen JT, Junttila JM, Anttonen O, Kenttä TV, Aro AL, et al. Prevalence and prognostic significance of fragmented QRS complex in middle-aged subjects with and without clinical or electrocardiographic evidence of cardiac disease. Am J Cardiol 2014;114:141-7.

22. Adar A, Kiriş A, Ulusoy Ş, ÖZkan G, Bektaş H, Okutucu S, et al. Fragmented $Q R S$ is associated with subclinical left ventricular dysfunction in patients with chronic kidney disease. Acta Cardiol 2014;69:385-90.

23. Liu P, Wu J, Wang L, Han D, Sun C, Sun J. The prevalence of fragmented QRS and its relationship with left ventricular systolic function in chronic kidney disease. J Int Med Res 2019; 030006051989079.

24. Zema MJ, Kligfield P. ECG poor R-wave progression: review and synthesis. Arch Intern Med 1982;142:1145-8.

25. Rizk DV, Gutierrez O, Levitan EB, McClellan WM, Safford M, Soliman EZ, et al. Prevalence and prognosis of unrecognized myocardial infarctions in chronic kidney disease. Nephrol Dial Transplant 2012;27:3482-8.

26. Farag AA, AlJaroudi W, Neill J, Doppalapudi H, Kumar V, Rizk D, et al. Prognostic value of silent myocardial infarction in patients with chronic kidney disease being evaluated for kidney transplantation. Int J Cardiol 2017;249:377-82.

27. El-Sherif N, Turitto G. Electrolyte disorders and arrhythmogenesis. Cardiol J 2011;18:233-45.

28. Nwankwo EA, Ummate I, Wudiri W. Prevalence of electrocardiographic left ventricular hypertrophy among incident dialysis patients in maiduguri, Nigeria. Res JMedicine Med Sci 2007;2:1-4.

29. Reddy BS. Assessment of ECG and echo findings among with chronic kidney disease patients. Scholars J Appl Med Sci 2017;5: 3475-80.

30. Badheka AO, Rathod A, Marzouka GR, Patel N, Bokhari SS, Moscucci M, et al. Isolated nonspecific ST-segment and T-wave 
abnormalities in a cross-sectional United States population and mortality (from NHANES III). Am J Cardiol 2012;110:521-5.

31. Kuhn L, Rose L. ECG interpretation Part 1: understanding mean electrical Axis. J Emerg Nurs 2008;34:530-4.

32. Rodriguez-Padial L, Akerström F, Barderas M, Vivanco F, Arias MA, Segura J, et al. Progression of renal insufficiency in patients with essential hypertension treated with renin angiotensin aldosterone system blockers: an electrocardiographic correlation. Diseases 2017;5:33.

33. Korkmaz A, Yıldız A, Kundi H, Başyigit F, Gürsoy HT, Elalmış ÖU, et al. Can hemodialysis change QRS axis in patients without cardiovascular disease? Turk Kardiyol Dernegi Arsivi 2018;46: 276-82.

34. Flueckiger P, Pastan S, Goyal A, McClellan WW, Patzer RE. Associations of ECG interval prolongations with mortality among ESRD patients evaluated for renal transplantation. Ann Transplant 2014;19:257-68.

35. Mandić A, Tomić M, Petrov B, Romic Z. Atrial fibrillation, atrioventricular blocks and bundle branch blocks in hemodialysis patients. Coll Antropol 2012;36:1395-9.

36. Boriani G, Savelieva I, Dan G-A, Deharo JC, Ferro C, Israel CW, et al. Chronic kidney disease in patients with cardiac rhythm disturbances or implantable electrical devices: clinical significance and implications for decision making-a position paper of the European Heart Rhythm Association endorsed by the Heart Rhythm Societ. EPP Eur 2015;17:1169-96.

37. Lilly LS. Pathophysiology of Heart Disease., 6th ed. Philadelphia: Wolters Kluwer - Medknow Publications; 2016.

38. Take Y, Morita H. Fragmented QRS: what is the meaning? Indian Pacing Electrophysiol J 2012;12:213.

39. Surawicz B, Childers R, Deal BJ, Gettes LS. AHA/ACCF/HRS Recommendations for the standardization and interpretation of the electrocardiogram: part III: intraventricular conduction disturbances A scientific statement from the American heart association electrocardiography and arrhythmias committee. J Am Coll Cardiol 2009;53:976-81.

40. Kim S-H, Kwak MH, Kim HJ, Nam GB, Choi KJ, Kim YH. Prevalence and positive predictive value of poor $\mathrm{R}$-wave progression and impact of the cardiothoracic ratio. Korean Circ J 2009;39: 418-22.

41. Tsao CW, Josephson ME, Hauser TH, O’Halloran TD, Agarwal A, Manning WJ, et al. Accuracy of electrocardiographic criteria for atrial enlargement: validation with cardiovascular magnetic resonance. J Cardiovasc Magn Reson 2008;10:7.

42. Sklyar E, Ginelli P, Barton A, Peralta R, Bella JN. Validity of electrocardiographic criteria for increased left ventricular mass in young patients in the general population. World J Cardiol 2017;9: 248-54.

43. Whitman IR, Patel VV, Soliman EZ, Bluemke DA, Praestgaard A, Jain $A$, et al. Validity of the surface electrocardiogram criteria for right ventricular hypertrophy: the MESA-RV Study (Multi-Ethnic Study of Atherosclerosis-Right Ventricle). J Am Coll Cardiol 2014; 63:672-81.

44. Ibanez B, James S, Agewall S, Antunes MJ, Bucciarelli-Ducci C, Bueno $\mathrm{H}$, et al. ESC Guidelines for the management of acute myocardial infarction in patients presenting with ST-segment elevation. Eur Heart J 2018 2017;39:119-77.

45. Hanna EB, Glancy DL. ST-segment depression and T-wave inversion: classification, differential diagnosis, and caveats | Cleveland Clinic Journal of Medicine. Cleve Clin J Med 2011;78: 404-14.

46. Bao H, Cai H, Zhao Y, Huang X, Fan F, Zhang C, et al. Nonspecific ST-T changes associated with unsatisfactory blood pressure control among adults with hypertension in China: evidence from the CSPPT study. Medicine (Baltim) 2017;96:e6423.

47. Arjmand A, Eshraghi A, Sani ZA, Firouzi A, Sanati HR, Nezami H, et al. Value of pathologic $Q$ wave in surface electrocardiography in the prediction of myocardial nonviability: a cardiac magnetic resonance imaging-based study. J Adv Pharm Technol Research 2018;9:162.

48. Pappal R, Espina I, Rafique Z. Peaked T-waves and potassium: the reliability of peaked T-waves as indicators of hyperkalemia in endstage renal patients undergoing hemodialysis. Am J Undergrad Res 2016;13.

49. Andrianto A, Dewi PR. Clinical implications of low-voltage electrocardiogram. Indones J Cardiol 2017;206-12. 